\title{
Autism Spectrum Disorders in Mali: Parental concerns about child developmental milestones and late diagnostic age
}

Modibo Sangare ( $\nabla$ mouadib@gwu.edu )

USTTB https://orcid.org/0000-0001-7519-918X

Ya Diarra

USTTB

Djeneba Konate

USTTB

Mohamed S Haidara

USTTB

Adama Karembe

USTTB

Boureima Keita

USTTB

Housseini Dolo

USTTB

Modibo Kouyate

USTTB

Fatoumata Doumbia

USTTB

Oumar Sidibe

USTTB

Seidina Diakite

USTTB

Kassoum Kayentao

USTTB

Drissa Traore

USTTB

Amadou Toure

USTTB

Seydou Doumbia

USTTB

Mahamadou Diakite 
USTTB

\section{Hyung-Goo Kim}

Qatar Biomedical Research Institute

Gordon A Awandare

WACCBIP

\section{Research}

Keywords: Autism, parental concerns, early screening, developmental milestones, Mali

Posted Date: July 13th, 2020

DOI: https://doi.org/10.21203/rs.3.rs-28746/v2

License: (c) (i) This work is licensed under a Creative Commons Attribution 4.0 International License. Read Full License 


\section{Abstract}

Background: In Mali, the national health facility-based prevalence of autism spectrum disorders (ASD) was $4.5 \%(105 / 2,343)$ and the age of first medical visit for autistic children was around 7 years old in 2018. Parental recognition of developmental abnormalities initiates the early autism detection and diagnosis. Our aim was to investigate if parental concerns were associated with early first medical visits and subsequent ASD diagnostic in Mali.

Methods: We conducted a pilot study from November 2017 to July 2019. We surveyed parents of 57 out of 60 available autistic children aged 3-14 years old.

Results: Parents were concerned over verbal communication in $54.1 \%$ and reciprocal social interaction in 43.8\%. Children with ASD had their first medical visit after 18 months old in $66.7 \%, \geq$ two medical visits in $87.7 \%$, and were identified after 36 months old in $76.8 \%$.

Conclusion: Parental concerns were not significantly associated with early first medical visit and ASD identification. Our results will guide future full scale studies on parental concerns in ASD in Mali.

\section{Background}

Autism spectrum disorders (ASD) affect 1 in 59 children aged 8 years old in the United States of America (U.S.A.) [1]. ASD are recognized as an emerging global public health concern due to the increasing worldwide prevalence and awareness along the need for early diagnostic and lifelong care [2,3]. Almost everything we know about ASD still comes from the World Bank high-income countries mainly. In subSahara Africa, the stigma and unmet needs of parents and children with ASD are considerable while the prevalence of ASD is still unknown [4-6]. In Mali, the health facility-based prevalence of ASD was 4.5\% $(105 / 2,343)$ in 2018 [7].

Early ASD diagnosis is very important because it helps to ensure appropriate services are offered and because this may improve prognosis [8,9]. Early intervention in ASD requires early detection, which depends on early screening. Various early autism screening tools have been developed in the U.S. to promote early autism risk detection [10]. In developed countries, the online version of the Modified checklist for autism in toddlers-Revised/follow up (M-CHAT-R/F) and the social communication questionnaire (SCQ) are available to parents who suspect their children at risk of ASD [11]. In Mali, we have validated the M-CHAT-R and SCQ in 2017-2018 to screen ASD in toddlers aged 18-24 months old and people aged 4-20 years old suspected with ASD, respectively [12]. Timely ASD diagnostic requires early detection, which greatly depends on parental recognition of developmental abnormalities [13]. In the U.S.A, parental concerns of childhood developmental abnormalities have been associated with early or late ASD screening and diagnostic as well as the overall well-being of autistic children [14,15]. In general, initial concerns about the autistic child's development come first from their parents in up to $80 \%$ [16]. Developmental motor delays during early childhood may represent an important predictor for ASD diagnostic $[17,18]$. In high risk children, parent-reported concerns can improve the early recognition of 
ASD [19]. However, research in the U.S.A. has demonstrated that socio-economic ranking of the parents correlate with the specific of the parental concerns in children suspected with ASD. For instance, parents with high socio-economic status were 8.5 times more concerned about the children being at risk of ASD as compared to those with low social economic status [20]. Parents with high socio-economic status tend to be those with high education level as well. They can afford healthcare to benfit the most from the ASD screening, monitor and surveillance system in the country $[12,13,18]$.

In Mali, one of the poorest countries in the world, women have a higher unschooling rate and struggle the most for their daily living [21]. The literacy rate is also one of the lowest in the world (33.1\%) in people aged 15 years old and above [22]. In addition, early child visits and autism screening are neither mandatory nor systematic in the Malian health system. After the validation of the M-CHAT-R/F and the SCQ in Mali, we wondered how effective these tools would be in the early ASD screening and diagnostic in our socio-cultural setting. We hypothesized that parental concerns on childhood developmental abnormalities could guide our ASD awareness campaigns and promote the use of M-CHAT-R and the SCQ for the early ASD risk screening in Mali. This original work was aimed to investigate the association between the child age at the first medical visit, as an indicator of the age of ASD diagnostic, and the parental concerns about their children's development abnormalities in Mali.

\section{Methods}

We conducted a descriptive cross-sectional pilot study from November 2017 to July 2019 in Bamako. In this study, we included all 57 out of 60 available autistic children aged 3-14 years old who were already enrolled into our autism genetic family study in Bamako. Our study was conducted in three phases. First, potential study participants were screened using the social communication questionnaire (SCQ) at a private medical clinic "Kaidara" downtown Bamako, the capital city and the cutoff score of $>15$ was used as the main inclusion criterium. Second, screened potential study participants underwent a thorough medical visit by a multidisciplinary team (a senior clinical psychologist, a senior child psychiatrist, a neuro-pediatrician, a neurologist, a resident in psychiatry and a resident in pediatrics). Those who did not have a brain CT scan at inclusion ( $n=40)$ underwent brain CT scan by an experienced neuroradiologist. All the potential study participants did eye and ear exams by a senior ear, nose \& throat (ENT) specialist and a certified junior ophthalmologist to exclude any medical condition, which could explain the child's deficit in social interaction. Third, study participants were selected based on presence of the signs and symptoms of autism spectrum disorders (dyad of ASD in DSM-V) and the normal brain CT Scan exam (or at least the absence of a structural cerebral lesion that can explain the child's condition). We interviewed parents of our study participants during home visits to administer our study questionnaire (see supplemental material). After verbal informed consent, we collected information on the age of developmental milestones of their autistic children. Our questions to the mothers of qautistic children were directed to determine the age at which the child was able to do specific task for the first time. Our questions pertained to the following child developmental domains: reciprocal social interaction, verbal communication, and motor skills. We also inquired about the presence of repetitive behaviors and other disorders (epilepsy, strabismus, and absence of crying at birth). Autistic children and their parents were 
compensated for their study participation at an approved rate by the Malian ethical committee at the Faculty of Medicine, Pharmacy and Odontostomatology (FMPOS), Bamako, Mali. Our study protocol, consent form and questionnaire were approved by the ethical committee at the FMPOS on July $16^{\text {th }}$, 2016. Completed questionnaires were coded without any identifiable personal information. In the database created, data were analyzed with SPSS version 25 . We determined the median and mean age for each childhood developmental milestone with a standard deviation and the extreme ages (minimum and maximum). To diagnose ASD, we used the criteria of DSM-IV [23]. To determine the factors associated with a delayed first medical consultation for autistic children in our cohort, we used chi square or Fischer exact test to compare the proportions (before and after a cutoff age of 18 months old for early ASD risk screening and 36 months old for early ASD diagnosis) of the presence of a targeted factor (male gender, Bambara ethnicity, impaired reciprocal social interaction, impaired verbal communication, repetitive behaviors, other disorders). Other disorders represented the presence of epilepsy, presence of strabismus and the absence of crying at birth. $\mathrm{p}^{\text {-value }}<0.05$ was considered statistically significant.

\section{Results}

Among 57 surveyed autistic children aged 3-14 years old, the sex-ratio was 1.5 in favor of male. The first medical visit was at/after the age of 18 months old in $66.7 \%$. The diagnosis of ASD was made at/after the age of 36 months old in $76.8 \%$. Autistic children had at least two medical visits before the ASD diagnosis in $87.7 \%$ (Table 1 ).

Table 1 Description of the study population 


\begin{tabular}{|c|c|c|c|}
\hline Characteristics & & Frequency & $\%$ \\
\hline \multirow[t]{3}{*}{ Gender } & Male & 34 & 59.6 \\
\hline & Female & 23 & 40.4 \\
\hline & Total & 57 & 100 \\
\hline \multirow[t]{3}{*}{ Ethnicity } & Bambara & 23 & 40.4 \\
\hline & Others & 34 & 59.6 \\
\hline & Total & 57 & 100 \\
\hline \multirow[t]{3}{*}{ Age of first medical consultation } & $\leq 18$ months & 19 & 33,3 \\
\hline & $>18$ months & 38 & 66,7 \\
\hline & Total & 57 & 100 \\
\hline \multirow[t]{3}{*}{ Age of ASD identification } & $\leq 36$ months & 13 & 23.2 \\
\hline & $>36$ months & 43 & 76.8 \\
\hline & Total & 57 & 100 \\
\hline \multirow[t]{4}{*}{ Health care provider } & Conventional medical practitioner & 23 & 40.3 \\
\hline & Traditional medical practitioner & 7 & 12.3 \\
\hline & Both & 27 & 47.4 \\
\hline & Total & 57 & 100 \\
\hline \multirow[t]{3}{*}{ Number of medical consultations before diagnosis } & $\leq 2$ times per child & 7 & 12.3 \\
\hline & $>2$ times per child & 50 & 87.7 \\
\hline & Total & 57 & 100 \\
\hline
\end{tabular}

Parental concerns on their children's development were mostly about verbal communication (54.1\%) and reciprocal social interaction (43.8\%) (Table 2$)$.

Table 2 Parental concerns by developmental domains of autistic children before and after age 36 months in Mali

\begin{tabular}{|c|c|c|}
\hline Child's developmental domains & Frequency $\quad(\mathrm{N}=57)$ & $\%$ \\
\hline Verbal communication & 32 & $54.1 \%$ \\
\hline Reciprocal social interaction & 25 & $43.8 \%$ \\
\hline Repetitive behaviors & 6 & $10.5 \%$ \\
\hline Other disorders ${ }^{1}$ & 30 & $52.6 \%$ \\
\hline
\end{tabular}

The median age of imitation was 24 months old with the extremes of 4 and 168 months old (Table 3 ). 
Table 3 Developmental age of key milestones acquisition for autistic Malian children

\begin{tabular}{|c|c|c|}
\hline Child developmental milestones & \multicolumn{2}{|c|}{ Age of acquisition (months old) } \\
\hline Reciprocal social interaction (being able) & Median & Mean \pm SD [Min.-Max.] \\
\hline To smile & 4.00 & $7.66 \pm 7.9[2-36]$ \\
\hline To applaude & 24.00 & $36.17 \pm 36.9[5-132]$ \\
\hline To imitate an adult & 24.00 & $45.23 \pm 44.8[4-168]$ \\
\hline $\begin{array}{l}\text { To show body parts on request } \\
\text { To participate in un/dressing }\end{array}$ & $\begin{array}{l}36.00 \\
42.00\end{array}$ & $\begin{array}{l}52.55 \pm 40.5[9-156] \\
1 . \pm 44.2[12-180]\end{array}$ \\
\hline Verbal communication & Median & Mean \pm SD [Min.-Max.] \\
\hline To utter high-pitched crying & 7.00 & $16.10 \pm 14.9[3-144]$ \\
\hline To say several syllables & 21.00 & $31.74 \pm 26.8[5-84]$ \\
\hline To tell a story & 49.00 & $50.4 \pm 21.5[36-99]$ \\
\hline Motor skill acquisition & Median & Mean \pm SD [Min.- Max.] \\
\hline To hold his/her head & 6.00 & $8.9 \pm 8.0[3-36]$ \\
\hline To reach for an object & 7.00 & $16.1 \pm 23.8[3-144]$ \\
\hline To move in bed by rotation & 7.00 & $11.1 \pm 10.7[2-48]$ \\
\hline To make pedaling movements & 6.00 & $10.5 \pm 9.6[2-36]$ \\
\hline $\begin{array}{l}\text { To sit with support } \\
\text { To turn around on his/her back }\end{array}$ & $\begin{array}{l}6.00 \\
8.50\end{array}$ & $\begin{array}{l}12 \pm 16.8[2-108] \\
14.3 \pm 14.6[3-84]\end{array}$ \\
\hline To put his/her feet in his/her mouth & 7.50 & $14.7 \pm 16.3[2-84]$ \\
\hline To sit without support & 7.00 & $11.7 \pm 10.7[3-48]$ \\
\hline To know how to stretch his/her arms & 7.00 & $13.6 \pm 13.9[3-72]$ \\
\hline To sit from flat back position & 9.00 & $17.5 \pm 26.8[4-84]$ \\
\hline To crawl & 10.00 & $16.8 \pm 16.6[4-96]$ \\
\hline To stand with/out support & 13.50 & $21.1 \pm 13.6[4-84]$ \\
\hline To walk without support & 14.50 & $19.5 \pm 44.8[7-72]$ \\
\hline To eat alone & 25.00 & $36.6 \pm 32.3[3-144]$ \\
\hline To take off his/her shoes & 48.00 & $57.1 \pm 38.8[13-180]$ \\
\hline To jump with joined feet & 30.00 & $37.2 \pm 18.3[17-96]$ \\
\hline To button his/her cloth & 60.00 & $64.8 \pm 41.5[15-180]$ \\
\hline
\end{tabular}


Page $8 / 19$ 
None of our targeted factors (gender, ethinicity, impaired verbal communication, impaired reciprocal social interaction, repetitive behaviors, and other disorders including epilepsy, strabismus, and absence of crying at birth) was significantly associated with a delayed age of first medical visit at/after the age of 18 months old (Table 4) and 36 months old time points (Table 5) all p>0.05.

Table 4 Factors associated with delayed first medical consultation for autistic children before and after age 18 months

\begin{tabular}{|c|c|c|c|c|c|}
\hline \multirow[t]{2}{*}{ Factors } & \multicolumn{4}{|c|}{ Age at first medical consultation } & \multirow[t]{2}{*}{ p-value } \\
\hline & & $\leq 18$ months $\mathrm{N}(\%)$ & $>18$ months & Total & \\
\hline \multirow{4}{*}{ Gender } & $M 0_{0}$ & $c(2)^{1} 10$, & 17 (7) & (100) & \multirow{4}{*}{0.628} \\
\hline & & $0(20.170)$ & (1) & & \\
\hline & Female & $12(35.3 \%)$ & $22(64.7 \%)$ & $34(100 \%)$ & \\
\hline & Total & $18(31.6 \%)$ & $39(68.4 \%)$ & $57(100 \%)$ & \\
\hline \multirow[t]{3}{*}{ Ethnicity } & Bambara & $9(39.0 \%)$ & $14(61.0 \%)$ & $23(100 \%)$ & \multirow[t]{3}{*}{0.518} \\
\hline & Others & $9(26.5 \%)$ & $25(73.5 \%)$ & $34(100 \%)$ & \\
\hline & Total & $18(31.6 \%)$ & $39(68.4 \%)$ & $57(100 \%)$ & \\
\hline \multirow[t]{3}{*}{ Impaired verbal communication } & Yes & $9(39.0 \%)$ & $22(71.0 \%)$ & $31(100 \%)$ & \multirow[t]{3}{*}{0.805} \\
\hline & No & $9(34.6 \%)$ & $17(65.4 \%)$ & $26(100 \%)$ & \\
\hline & Total & $18(31.6 \%)$ & $39(68.4 \%)$ & $57(100 \%)$ & \\
\hline \multirow[t]{3}{*}{ Impaired reciprocal social interaction } & Yes & $9(36.0 \%)$ & $16(64.0 \%)$ & 25 (100\%) & \multirow[t]{3}{*}{0.695} \\
\hline & No & $9(28.1 \%)$ & $23(71.9 \%)$ & 32 (100\%) & \\
\hline & Total & $18(31.6 \%)$ & $39(68.4 \%)$ & 57 (100\%) & \\
\hline \multirow[t]{3}{*}{ Repetitive behaviors } & Yes & $2(33.3 \%)$ & $4(66.7 \%)$ & $6(100 \%)$ & \multirow[t]{3}{*}{1.000} \\
\hline & No & $16(31.4 \%)$ & $35(68.6 \%)$ & 51 (100\%) & \\
\hline & Total & $18(31.6 \%)$ & $39(68.4 \%)$ & $57(100 \%)$ & \\
\hline \multirow[t]{3}{*}{ Other disorders ${ }^{1}$} & Yes & $9(30.0 \%)$ & $21(70.0 \%)$ & $30(100 \%)$ & \multirow[t]{3}{*}{0.88} \\
\hline & No & $9(33.3 \%)$ & $18(66.7 \%)$ & $27(100 \%)$ & \\
\hline & Total & $18(31.6 \%)$ & $39(68.4 \%)$ & $57(100 \%)$ & \\
\hline
\end{tabular}

1Epilepsy, strabismus, and absence of crying at birth

Table 5 Factors associated with delayed first medical consultation for autistic children before and after age 36 months 


\begin{tabular}{|c|c|c|c|c|c|}
\hline \multirow{3}{*}{$\begin{array}{ll}\text { Factors } \\
\end{array}$} & \multicolumn{4}{|c|}{ Age at identification } & \multirow[t]{3}{*}{ p-value } \\
\hline & & - 20 month & $>36$ months & Total & \\
\hline & \multicolumn{3}{|c|}{ N (\%) } & & \\
\hline \multirow[t]{3}{*}{ Gender } & Male & $3(13.0 \%)$ & $20(87.0 \%)$ & $23(100 \%)$ & 1.000 \\
\hline & Female & $4(11.8 \%)$ & $30(88.2 \%)$ & $34(100 \%)$ & \\
\hline & Total & $7(12.3 \%)$ & $50(87.7 \%)$ & $57(100 \%)$ & \\
\hline \multirow[t]{3}{*}{ Ethnicity } & Bambara & $1(4.3 \%)$ & $22(95.6 \%)$ & $23(100 \%)$ & 0.4275 \\
\hline & Others & $6(17.6 \%)$ & $28(82.4 \%)$ & $34(100 \%)$ & \\
\hline & Total & $7(12.3 \%)$ & $50(87.7 \%)$ & $57(100 \%)$ & \\
\hline \multirow[t]{3}{*}{ Impaired verbal communication } & Yes & $5(15.6 \%)$ & $27(84.4 \%)$ & $32(100 \%)$ & 0.7497 \\
\hline & No & $2(8.0 \%)$ & $23(92.0 \%)$ & 25 (100\%) & \\
\hline & Total & $7(12.3 \%)$ & $50(87.7 \%)$ & $57(100 \%)$ & \\
\hline \multirow[t]{3}{*}{ Impaired reciprocal social interaction } & Yes & $3(12.0 \%)$ & $22(88.0 \%)$ & $25(100 \%)$ & 1.000 \\
\hline & No & $4(12.5 \%)$ & 28 (87.5\%) & 32 (100\%) & \\
\hline & Total & $7(12.3 \%)$ & $50(87.7 \%)$ & 57 (100\%) & \\
\hline \multirow[t]{3}{*}{ Repetitive behaviors } & Yes & $0(0.0 \%)$ & $6(100.0 \%)$ & $6(100 \%)$ & 1.000 \\
\hline & No & $7(13.7 \%)$ & 44 (86.3\%) & $51(100 \%)$ & \\
\hline & Total & 7 (12.3\%) & $50(87.7 \%)$ & 57 (100\%) & \\
\hline \multirow[t]{3}{*}{ Other disorders $^{1}$} & Yes & $3(10.0 \%)$ & 27 (90.0\%) & $30(100 \%)$ & 1.0000 \\
\hline & No & $4(14.8 \%)$ & $23(85.2 \%)$ & 27 (100\%) & \\
\hline & Total & 7 (12.3\%) & $50(87.7 \%)$ & 57 (100\%) & \\
\hline
\end{tabular}

${ }^{1}$ Epilepsy, strabismus, and absence of crying at birth

\section{Discussion}

Children aged 18 to 24 months are screened for ASD to assist in early detection, consistent with current American Academy of Pediatrics' recommendations [24]. Despite the advances in ASD screening and evaluation, the mean age of diagnosis is still 4-5 years [25]. The age of ASD diagnosis depends on many factors and to label a child "autistic" may require a multidisciplinary team [26] or multiple medical visits (4-5 on average with the extremes of 1 and 29) [27]. While the high demand of services due to a recent increase in ASD prevalence delays its diagnosis in developed countries, the lack of trained health professionals and the socio-cultural representation of the disorder may prevail in Mali. Similar to subSahara Africa, in the Arab world, culture may significantly influence the age of noticing abnormality and the ways of investigating and treating autism [28]. 
The age of ASD identification was at/after the age of 36 months old in 76.8\% (Table 1). In two separate national surveys in the U.S.A., the 2011-2012 National Survey of Children's Health $(n=95,677)$ and the 2009-2010 National Survey of Children with Special Health Care Needs $(n=371,617)$, many parents of children with ASD reported identification after 3 years old with $1 / 3$ to $1 / 2$ of cases after 6 years old [28].

In our cohort, parental concerns on their children's development were mostly about verbal communication (54.1\%) and reciprocal social interaction (43.8\%) (Table 2). This result corroborates the findings of Richards et al. They reported that over $90 \%(n=532)$ of the parents brought up concerns during well child visits and $78.6 \%$ were about speech and verbal communication [29]. Children whose parents expressed concerns about their child's verbal communication experienced earlier ages for all outcomes when compared to children of parents who did not have verbal communication concerns [30]. Such finding highlights the evolution of parental concerns over time. In mid-2000s, parents of autistic children used to be concerned over either a delayed diagnosis of physical disabilities, such as hearing impairment, cerebral palsy [31], learning difficulty, being bullied, stress-coping, or achievement [32].

The median age of being able to smile (social and non-social) for the first time was 4 months old and the mean age was 7.7 months old \pm 7.9 with the extremes of 2 and 36 months old (Table 3 ). Anticipatory smiling levels in the first year may predict ASD diagnosis or continuous ASD severity outcomes [33]. The median age of imitation was 24 months and the average age of 45.23 months \pm 44.8 with the extremes of 4 and 168 months old (Table 3). Immediate and deferred imitations of adults by children with ASD were strongly associated with language ability at age 3-4 years and communication development from age 4 to 6.5 years [34], but the loss of social communication skills is highly variable (its rate, timing and severity) in ASD and it usually occurs in the period between 9 and 24 months $[35,36]$.

The median age of storytelling in our cohort was 49 months and the mean age was 50.4 months \pm 21.5 with the extremes of 36 and 99 months (Table 3). Difficulties in storytelling have been reported in children with ASD $[37,38]$. While the contribution of problematic use of subject pronoun has been demonstrated in the difficulties in storytelling in school-aged children with ASD [39], speculation has been on whether or not difficulties in orientation in time and space play an important role in the process [40].

Motor development is critical to the overall development of the child. In our cohort, the age of motor skill acquisition was very variable. For instance, the mean age of reaching out for an object was 16.1 months \pm 23.8 with the extremes 3 and 144 months (Table 3 ). The gross and fine motor skills of young children with ASD are delayed and become progressively more delayed with age [41,42], but the great variability in motor skill acquisition makes it challenging the universality for health professionals [43]. The median age of walking (AOW) in our cohort was 14.50 months and the mean age was 19.5 months \pm 44.8 with the extremes of 7 and 72 months (Table 3). Reindal et al. reported a mean AOW of 15.3 months \pm 5.5 in children with ASD versus 14.1 months \pm 3.4 . AOW is reported to be later in autism spectrum disorder (ASD) compared with typical normal development [44].

None of our targeted factors (male gender, Bambara ethnicity, impaired reciprocal social interaction, impaired verbal communication, repetitive behaviors, the presence of epilepsy, presence of strabismus, 
and the absence of crying at birth) was significantly associated with the age of first medical visit (the cutoff was 18 months) or the age of identification of autistic disorder (the cutoff was 36 months (Tables 4-5). This finding might have resulted from the small size of our sample. Otherwise, evidence from the literature are compelling for the association of some (if not all) of these studied factors with early detection and diagnosis of autism spectrum disorders.

Parental concerns are more pronounced in males and females with ASD. This may have many plausible explanations. First, even with higher ASD prevalence in both sexes, core ASD symptomology are easily presentable in males, and females are too good in camouflaging their symptoms, which may result in sex differences in parental concerns after age 5 years [45-50]. Second, females experienced less unusual stereotyped and repetitive behaviors than males due to genetic ( $Y$ chromosome) and hormonal factors (fetal testosterone) and they have an increased prevalence of internalizing problems [47,51]. Third, females were found to receive lower scores than males particularly on modules 2 and 3 of the Childhood Autism Rating Scale scores (CARS) [52]. Finally, Baron-Cohen's extreme male theory may induce a stronger examiner bias toward males than females with ASD [53].

Black parents reported significantly fewer autism concerns and fewer social and restricted and repetitive behavior concerns as compared to White parents [54]. The Bambara are the largest ethnic group in Mali with up to $36.5 \%$ of the total population. They also present in significant percentages in Guinea Conakry, Burkina Faso, Niger, Ivory Coast, and Mauritania [55]. In addition, the other disorders in Tables 3-5 (epilepsy, strabismus, and absence of crying at birth) are very frequent in autism [56-58]. The absence of crying at birth and seizure episode in childhood were highly associated with autism risk in Brazil (OR 5.75; 95\% Cl 3.37-9.81) [10]. Even though, strabismus has a low prevalence in Africa [59], it has a strong cultural representation in the West African society in general and in Mali in particular. It is referred to as "the hen is looking at the cloudy sky" in Mali and it is a distinctive and particular trait which, a child can be labeled with among his/her peer.

Which one of the impaired reciprocal social interaction, afflicted verbal communication and repetitive behaviors in children with ASD draws first the attention of parents? The answer to this question depends on multiple factors. Truly, ASD is a spectrum in the real sense of the word. When all domains of the child's development are affected moderately or severely at the same time, parents usually notice as early as possible, especially when they have another child with normal developmental for comparison [60]. When language skills lag far behind, parental concerns habitually raise between 18 and 24 months old of age $[29,61]$.

Altogether, assessing parental concerns about children with ASD may be more challenging and more complex than one may initially think. Core symptoms of ASD alone may not explain at which extent parents are concerned and stressed out their child development and well-being. A more comprehensive assessment should consider other aspects such as sleep and eating problems, parenting stress, the specific burden on mothers with subsequent poor marital relationship [53,60-63]. 
The main limitation of this study was that the mothers might have biased some of their answers. As our pool of autistic children continues to grow, we will continue to administer this questionnaire with a statistically determined minimal sample size. Meanwhile, a 2-year prospective follow up study on parental concerns and the score on the M-CHAT-R is in planning.

\section{Conclusion}

After this pilot study, we surveyed parents of 57 out 60 available autistic children with ASD aged 3-14 years. Parental concerns on their children's development were mostly about verbal communication (54.1\%) and reciprocal social interaction (43.8\%). The first medical visit was after the age of 18 months old in $66.7 \%$; autistic children had at least two medical visits before the ASD diagnosis in $87.7 \%$. The age of ASD identification was after 36 months old in $76.8 \%$. No investigated factor was associated with the age of first medical visit and identification of ASD due to the small size of our sample. In the future, we will conceive an online version of our study questionnaire for a larger online survey across West Africa.

\section{List Of Abbreviations}

ASD: Autism Spectrum Disorders

AOW: Median age of walking

CARS: Childhood Autism Rating Scale scores

DSM-V: Diagnostic and Statistical Manual of Mental Disorders-V

ENT: Eye, nose \& throat

FMPOS: Faculty of Medicine, Pharmacy and Odontostomatology

M-CHAT-R/F: Modified checklist for autism in toddlers-Revised/follow up

SCQ: Social communication questionnaire

OR: Odd ratio

\section{Declarations}

Ethics approval and consent to participate: Our study protocol, consent form and questionnaire were approved by the ethical committee at the FMPOS. "All procedures performed in studies involving human participants were in accordance with the ethical standards of the institutional and/or national research committee (include name of committee + reference number) and with the 1964 Helsinki declaration and its later amendments or comparable ethical standards." Informed consent was obtained from all individual participants in the study. 
Consent for publication: "Not applicable"

Availability of data and materials: The datasets used and/or analyzed during the current study are available from the corresponding author on reasonable request.

Competing interests: None. The authors declare that they have no conflict of interest.

Funding: "Dr. Modibo Sangare, MD, PhD was supported by a postdoctoral fellowship from a DELTAS Africa grant (DEL-15-007: Awandare). The DELTAS Africa Initiative is an independent funding scheme of the African Academy of Sciences (AAS)'s Alliance for Accelerating Excellence in Science in Africa (AESA) and supported by the New Partnership for Africa's Development Planning and Coordinating Agency (NEPAD Agency) with funding from the Wellcome Trust (107755/Z/15/Z: Awandare) and the UK government. The views expressed in this publication are those of the author(s) and not necessarily those of AAS, NEPAD Agency, Wellcome Trust or the UK government." Dr. Modibo Sangare was also a grantee of the University of Sciences, Techniques and Technologies of Bamako, Ministry of Higher Education and Scientific Research of Mali.

Authors' contributions: All authors contributed to the study conception and design. Material preparation, data collection and analysis were performed by [Modibo SANGARE], [YA Diarra] and [Drissa TRAORE]. The first draft of the manuscript was written by [Modibo SANGARE] and all authors commented on previous versions of the manuscript. All authors read and approved the final manuscript.

Acknowledgements: We acknowledged Professor Marouf Keita, Professor Youssoufa Maiga, Professor Cheick Oumar Guinto, and Dr Mamadou Karambe for referring children with ASD to our research, all our study participants and their parents or guardians for the time and effort. We particularly thank Professor Daniel Geschwind, Professor Petrus de Vries and Dr Andrew Thurm for their useful inputs that guided our ASD research in Mali.

\section{References}

1. Baio J, Wiggins L, Christensen DL, Maenner MJ, Daniels J, Warren Z, Kurzius-Spencer M, Zahorodny W, Rosenberg CR, White T, Durkin MS, Imm P, Nikolaou L, Yeargin-Allsopp M, Lee L-C, Harrington R, Lopez M, Fitzgerald RT, Hewitt A, Pettygrove S, Constantino JN, Vehorn A, Shenouda J, Hall-Lande J, Braun KVN, Dowling NF. Prevalence of Autism Spectrum Disorder Among Children Aged 8 Years Autism and Developmental Disabilities Monitoring Network, 11 Sites, United States, 2014 [published correction appears in MMWR Morb Mortal Wkly Rep. 2018 May 18;67(19):564] [published correction appears in MMWR Morb Mortal Wkly Rep. 67(45), 1280. MMWR Surveill Summ, 2018;67:1-23.

2. Lyall K, Croen L, Daniels J, Fallin MD, Ladd-Acosta C, Lee BK, Park BY, Snyder NW, Schendel D, Volk H, Windham GC, and Newschaffer C. The Changing Epidemiology of Autism Spectrum Disorders. Annual review of public health. 2017;38, 81-102. 
3. Rosanoff MJ, Daniels AM, and Shih A. Autism: a (key) piece of the global mental health puzzle. Global mental health (Cambridge, England). 2015;2, e2.

4. Franz L, Chambers $N$, von Isenburg $M$, de Vries PJ. Autism spectrum disorder in sub-saharan Africa: $A$ comprehensive scoping review. Autism Res. 2017;10:723-749.

5. Tekola B, Baheretibeb Y, Roth I, Tilahun D, Fekadu A, Hanlon C, and Hoekstra RA. Challenges and opportunities to improve autism services in low-income countries: lessons from a situational analysis in Ethiopia. Glob Ment Health (Camb). 2016;3, e21. doi:10.1017/gmh.2016.17

6. Tilahun D, Hanlon C, Fekadu A, Tekola B, Baheretibeb Y, and Hoekstra RA. Stigma, explanatory models and unmet needs of caregivers of children with developmental disorders in a low-income African country: a cross-sectional facility-based survey. BMC Health Serv Res. 2016;16, 152. doi:10.1186/s12913-016-1383-9

7. Sangare M, Fousso F, Toure A, Ghislan V, Traore K, Coulibaly SP, Maiga B, Kouyate M, Sidibe O, Diakite SA, Dolo H, Coulibaly SY, Awandare GA, Coulibaly S, Togora A, Doumbia S, Coulibaly YI, Geschwind DH. Health facility-based prevalence and potential risk factors of autism spectrum disorders in Mali. AJNS. 2018;37:90-100.

8. Esposito G, Hiroi N, Scattoni ML. Cry, Baby, Cry: Expression of Distress As a Biomarker and Modulator in Autism Spectrum Disorder. International Journal of Neuropsychopharmacology. 2017;20:498-503.

9. Bieleninik L, Posserud MB, Geretsegger M, Thompson G, Elefant C, and Gold C. (2017). Tracing the temporal stability of autism spectrum diagnosis and severity as measured by the Autism Diagnostic Observation Schedule: A systematic review and meta-analysis. PLoS One. 2017;12(9), e0183160. doi:10.1371/journal.pone.0183160

10. Robins DL, Dumont-Mathieu TM. Early Screening for Autism Spectrum Disorders: Maia FA, Oliveira LMM, Almeida MTC, Alves MR, Saeger VSA, Silva VB, Oliveira VSD, Hercílio MJ, Brito MFSF, Silveira MF. Autism spectrum disorder and postnatal factors: A case-control study in Brazil. Revista Paulista de Pediatria. 2006 Epub July 18, 2019.https://dx.doi.org/10.1590/1984-0462/;2019;37;4;00006

11. Ben-Sasson, A., Robins, D.L., and Yom-Tov, E. Risk Assessment for Parents Who Suspect Their Child Has Autism Spectrum Disorder: Machine Learning Approach. J Med Internet Res. 2018;20:e134.

12. Sangare M, Toure HB, Toure A, Karembe A, Dolo H, Coulibaly YI, Kouyate M, Traore K, Diakité SA, Coulibaly S, Togora A, Guinto CO, Awandare GA, Doumbia S, Diakite M, Geschwind DH. Validation of two parent-reported autism spectrum disorders screening tools M-CHAT-R and SCQ in Bamako, Mali. 2019 Mar 11;15:100188. doi: 10.1016/j.ensci.2019.100188. eCollection 2019 Jun.

13. De Giacomo A, Fombonne E. Parental recognition of developmental abnormalities in autism. European Child \& Adolescent Psychiatry. 1998;7:131-136.

14. Ozonoff S, Young GS, Steinfeld MB, Hill MM, Cook I, Hutman T, Macari S, Rogers SJ, and Sigman M. How early do parent concerns predict later autism diagnosis?. Journal of developmental and behavioral pediatrics: JDBP. 2009;30(5):367-375.

15. Herlihy L, Knoch K, Vibert B, and Fein D. Parents' first concerns about toddlers with autism spectrum disorder: effect of sibling status. Autism: the international journal of research and practice. 
2015;19(1):20-28.

16. Garrido D, Carballo G, Artis J, Garcia-Retamero R. Timing of Parents' Concerns Related to Autism Spectrum Disorder and its Diagnosis: A Mediation Analysis. Span J Psychol. 2018; 27:E59.

17. Harris SR. Early motor delays as diagnosis clues in autism spectrum disorder. Eur J Pediatr. 2017;176:1259-1262.

18. Wilson RB, Enticott PG, Rinehart NJ. Motor development and delay: advances in assessment of motor skills in autism spectrum disorders. Curr Opin Neurol. 2018;31:134-139.

19. Sacrey LA, Zwaigenbaum L, Bryson S, Brian J, Smith IM, Roberts W, Szatmari P, Roncadin C, Garon N, Novak C, Vaillancourt T, McCormick T, MacKinnon B, Jilderda S, Armstrong V. Can parents' concerns predict autism spectrum disorder? A prospective study of high-risk siblings from 6 to 36 months of age. J Am Acad Child Adolesc Psychiatry. 2015;54:470-478.

20. Sun X, Allison C, Auyeung B, Baron-Cohen S, Brayne C. Parental concerns, socioeconomic status, and the risk of autism spectrum conditions in a population-based study. Res Dev Disabil. 2014;35:36783688 .

21. Simon D, Adams AM, Madhavan Women's social power, child nutrition and poverty in Mali. J. Biosoc. Sci. 2002;34(2), 193-213.

22. World Bank, Literacy Rate, Adult Total for Mali [SEADTLITRZSMLI], retrieved from FRED, Federal Reserve Bank of St. Louis; https://fred.stlouisfed.org/series/SEADTLITRZSMLI, September 14, 2019.

23. American Psychiatric Association. Diagnosis and statistical manual of mental disorders(4th ed., rev.). Washington DC: Author. 2000 (Pg. 75)

24. Zwaigenbaum L, Bauman ML, Fein D, Pierce K, Buie T, Davis PA, Newschaffer C, Robins DL, Wetherby A, Choueiri R., Kasari C, Stone WL, Yirmiya N, Estes A, Hansen RL, McPartland JC, Natowicz MR, Carter A, Granpeesheh D, Mailloux Z, Roley SS, Wagner S. Early Screening of Autism Spectrum Disorder: Recommendations for Practice and Research. Pediatrics. 2015;136:S4159.

25. Zwaigenbaum L, Penner M. Autism spectrum disorder: advances in diagnosis and evaluation. BMJ. 2018;361:k1674. doi: 10.1136/bmj.k1674.

26. Aubyn C, Stahmer AC, and Mandell DS. (). State Infant/Toddler Program Policies for Eligibility and Services Provision for Young Children with Autism. Adm Policy Ment Health. 2007;34:29-37.

27. Goin-Kochel RP, Mackintosh VH, Myers BJ. How many doctors does it take to make an autism spectrum diagnosis? Autism. 2006;10:439-451.

28. Hussein $H$, Taha GR, Almanasef $A$. Characteristics of autism spectrum disorders in a sample of egyptian and saudi patients: transcultural cross sectional study. Child Adolesc Psychiatry Ment Health. 2011;3:34.

29. Sheldrick RC, Maye PM, Carter AS. Age at First Identification of Autism Spectrum Disorder: An Analysis of Two US Surveys. J Am Acad Child Adolesc Psychiatry. 2017;56:313-320. 
30. Richards M, Mossey J, Robins DL. Parents' Concerns as they Relate to Their Child's Development and Later Diagnosis of Autism Spectrum Disorder. J Dev Behav Pediatr. 2016;37:532-540.

31. Zablotsky B, Colpe LJ, Pringle BA, Kogan MD, Rice C, Blumberg SJ. Age of parental concern, diagnosis, and service initiation among children with autism spectrum disorder. Am J Intellect Dev Disabil. 2017;122:49-61.

32. Caronna EB, Augustyn M, Zuckerman B. Revisiting Parental Concerns in the Age of Autism Spectrum Disorders: The Need to Help Parents in the Face of Uncertainty. Arch Pediatr Adolesc Med. 2007;161:406-408.

33. Lee LC, Harrington RA, Louie BB, Newschaffer CJ. Children with Autism: Quality of Life and Parental Concerns. J Autism Dev Disord. 2008;38:1147-1160.

34. Gangi, Devon N., "The Development of Anticipatory Smiling in Infants at Risk for Autism" (2012). Open Access Theses. 368. https://scholarlyrepository.miami.edu/oa_theses/368

35. Toth K, Munson J, Meltzoff AN, Dawson G. Early predictors of communication development in young children with autism spectrum disorder: joint attention, imitation, and toy play. $J$ Autism Dev Disord. 2006;36:993-1005.

36. Tager-Flusberg $\mathrm{H}$. The origins of social impairments in autism spectrum disorder: studies of infants at risk. Neural Netw. 2010;23:1072-1076.

37. Mitchell S, Cardy JO, Zwaigenbaum L. Differentiating autism spectrum disorder from other developmental delays in the first two years of life. Dev Disabil Res Rev. 2011;17:130-140.

38. Losh M, Gordon PC. Quantifying narrative ability in autism spectrum disorder: a computational linguistic analysis of narrative coherence. J Autism Dev Disord. 2014;44:3016-3025.

39. Tyrrell D, Logan A. A Review of the Literature Relating to the Use of Digital Storytelling (DS) on an iPad to Support Narrative Skill Development of a Child with Autism Spectrum Disorder (ASD). Reach. 2017;30:56-66.

40. Novogrodsky R. Subject pronoun use by children with autism spectrum disorders (ASD). Clin Linguist Phon. 2013;27:85-93.

41. Smith AD. Spatial navigation in autism spectrum disorders: a critical review. Front Psychol. 2015;6:31.

42. Lloyd M, MacDonald M, Lord C. Motor skills of toddlers with autism spectrum disorders. Autism. 2015;17:133-146.

43. Iverson JM, Shic F, Wall CA, Chawarska K, Curtin S, Estes A, Gardner JM, Hutman T, Landa, RJ, Levin AR, Libertus K, Messinger DS, Nelson CA, Ozonoff S, Sacrey LR, Sheperd K, Stone WL, Tager-Flusberg HB, Wolff JJ, Yirmiya N, Young GS.

Early motor abilities in infants at heightened versus low risk for ASD:A Baby Siblings

Research Consortium (BSRC) study. J Abnorm Psychol. 2019;128:69-80.

44. West KL. Infant Motor Development in Autism Spectrum Disorder: A Synthesis and Meta-analysis. Child Dev. 2018 doi: 10.1111/cdev.13086. 
45. Reindal L, Nærland T, Weidle B, Lydersen S, Andreassen OA, Sund AM. J Autism Dev Disord. 2019 Jul 5. https://doi.org/10.1007/s10803-019-04112-y

46. Ramsey RK, Nichols L, Ludwig NN, Fein D, Adamson LB, Robins DL. Brief Report: Sex Differences in Parental Concerns for Toddlers with Autism Risk. J Autism Dev Disord. 2018;48:4063-4069.

47. Parish-Morris J, Liberman MY, Cieri C, HerringtonJD, Yerys BE, Bateman L, Donaher J, Ferguson E, Pandey J, Schultz "Linguistic camouflage in girls with autism spectrum disorder." Molecular Autism. 2017;8:48.

48. Kreiser NL, White SW. ASD in Females: Are We Overstating the Gender Difference in Diagnosis? Clin Child Fam Psychol Rev. 2013; doi 10.1007/s10567-013-0148-9.

49. Hull L, Petrides KV, Allison C, Smith P, Baron-Cohen S, Lai MC, Mandy W. "Putting on My Best Normal": Social Camouflaging in Adults with Autism Spectrum Conditions. J Autism Dev Disord. 2017;47:2519-2534.

50. Lai MC, Lombardo MV, Ruigrok ANV, Chakrabarti B, Auyeung B, Szatmari P, Happé F, Baron-Cohen S, MRC AIMS Consortium. Quantifying and exploring camouflaging in men and women with autism. Autism. 2017;21:690-702.

51. Geelhand P, Bernard P, Klein O, van Tiel B, Kissine M. The role of gender in the perception of autism symptom severity and future behavioral development. Mol Autism. 2019;10,16.

52. Werling DM, Geschwind DH. Sex differences in autism spectrum disorders. Curr Opin Neurol. 2013;26:146-153.

53. Mussey J L, Ginn NC, Klinger LG. Are males and females with autism spectrum disorder more similar than we thought? Autism. 2017;21:733-737.

54. Goldman S. Opinion: Sex, Gender and the Diagnosis of Autism - A Biosocial View of the Male Preponderance. Res Autism Spectr Disord. 2013;7:675-679.

55. Donohue MR, Childs AW, Richards M, Robins DL. Race influences parent report of concerns about symptoms of autism spectrum disorder. Autism. 2019;23:100-111.

56. Too KK (2018 June 7). Largest Ethnic Groups In Mali. Retrieved from https://www.worldatlas.com/articles/largest-ethnic-groups-in-mali.html September 15, 2019

57. Kaplan M, Rimland B, \& Edelson SM. Strabismus in Autism Spectrum Disorder. Focus on Autism and Other Developmental Disabilities. 1999;14:101-105.

58. Saemundsen E, Ludvigsson P, Hilmarsdottir I, Rafnsson V. Autism spectrum disorders in children with seizures in the first year of life - a population-based study. Epilepsia. 2007;48:1724-1730.

59. Besag FM. Current controversies in the relationships between autism and epilepsy. Epilepsy Behav. 2015;47:143-146.

60. AkpeBA, Dawodu OA, Abadom Prevalence and pattern of strabismus in primary school pupils in Benin City, Nigeria. Niger J Ophthalmol. 2014;22:38-43.

61. Tager-Flusberg H, Caronna E. Language disorders: autism and other pervasive developmental disorders. Pediatr Clin North Am. 2007;54:469-481. 
62. Mazzone L, Postorino V, Siracusano M, Riccioni A, Curatolo P. The Relationship between Sleep Problems, Neurobiological Alterations, Core Symptoms of Autism Spectrum Disorder, and Psychiatric Comorbidities. J Clin Med. 2018;7:102.

63. Ledford JR, Gast DL. Feeding problems in children with autism spectrum disorders: A review. Focus on Autism and Other Developmental Disabilities. 2006;21:153-166.

64. Brobst JB, Clopton JR, \& Hendrick SS. Parenting Children With Autism Spectrum Disorders: The Couple's Relationship. Focus on Autism and Other Developmental Disabilities. 2009;24:38-49.

\section{Supplementary Files}

This is a list of supplementary files associated with this preprint. Click to download.

- Studyquestionnaire03022020.docx 